\title{
Patrón de asentamiento y uso del espacio. Precordillera de Arica, extremo norte de Chile, siglos X-XV
}

Modèle d'aménagement et d'utilisation de l'espace. Précordillère d'Arica, extrême nord du Chili, $X^{e}-X V^{e}$ siècles

Settlement pattern and the use of the space. Premountain range of Arica, Northern Chile, AD X - XV

Juan Chacama R.

\section{OpenEdition}

Journals

Edición electrónica

URL: http://journals.openedition.org/bifea/4892

DOI: $10.4000 /$ bifea.4892

ISSN: 2076-5827

Editor

Institut Français d'Études Andines

Edición impresa

Fecha de publicación: 1 diciembre 2005

Paginación: 357-378

ISSN: 0303-7495

Referencia electrónica

Juan Chacama R., «Patrón de asentamiento y uso del espacio. Precordillera de Arica, extremo norte de Chile, siglos X-XV », Bulletin de l'Institut français d'études andines [En línea], 34 (3) | 2005, Publicado el 08 diciembre 2005, consultado el 01 diciembre 2020. URL : http://journals.openedition.org/bifea/4892 ; DOI : https://doi.org/10.4000/bifea.4892

\section{cc) (†) $\ominus$}

Les contenus du Bulletin de l'Institut français d'études andines sont mis à disposition selon les termes de la licence Creative Commons Attribution - Pas d'Utilisation Commerciale - Pas de Modification 4.0 International. 


\title{
Patrón de asentamiento y uso del espacio. Precordillera de Arica, extremo norte de Chile, siglos $\mathrm{X}-\mathrm{XV}^{*}$
}

\author{
Juan Chacama R.**
}

\begin{abstract}
Resumen
Sobre la base de un trabajo previo de prospección y análisis de un conjunto de más de treinta sitios arqueológicos se presenta una aproximación a los patrones de asentamientos existentes en la precordillera de Arica, norte de Chile durante los siglos X al XV. Se proponen dos grandes patrones arquitectónicos: circular y rectangular, cada uno asociado a diferentes momentos de la prehistoria regional; el primero al período Intermedio Tardío y el segundo al período Tardío u Horizonte Inca. Se presenta una distribución espacial de ambos patrones y la forma de utilización del espacio productivo. Ambas situaciones, patrones arquitectónicos y uso del espacio constituye lo que denominamos en este trabajo patrones de asentamiento.
\end{abstract}

Palabras clave - patrones de asentamiento, siglos X al XV, precordillera de Arica - Chile, Andes del Sur

\section{Modèle d'aménagement et d'utilisation de l'espace. Précordillère d'Arica, extrême nord du Chili, $X^{e}-X^{e}$ siècles}

\section{Résumé}

À partir d'un travail préalable de prospection et d'analyse d'un ensemble de plus de trente sites archéologiques, I'auteur présente un essai de modèle d'aménagements existants dans la précordillère $d^{\prime}$ Arica, au nord du Chili, du $X^{e}$ au $X V^{e}$ siècles. Deux grands modèles architecturaux s'offrent à nous : circulaire ou rectangulaire, chacun associé à différents moments de la préhistoire régionale: le premier à la période Intermédiaire Récente et le deuxième à la période Récente ou l'époque Inca.

Este trabajo es el resultado del proyecto FONDECYT 1040296.

** Académico del Departamento de Arqueología y Museología. Universidad de Tarapacá, Arica - Chile. E-mail: jchacama@uta.cl 
La distribution spatiale des deux modèles est présentée ainsi que le mode d'utilisation de l'espace productif. Les deux cas, modèles architecturaux et d'utilisation de l'espace, constituent ce que nous appelons dans cet article un modèle d'aménagement.

Mots clés - modèles d'aménagemet, $X^{e}$ au XVe siècles, Précordillère d'Arica - Chili, Andes du Sud

\title{
Settlement pattern and the use of the space. Premountain range of Arica, Northern Chile, AD X - XV
}

\begin{abstract}
On the basis of the survey and analysis of a set of about of thirty archaeological sites, an approach is offered to the settlements patterns existing in the premountain range of Arica, northern Chile during centuries X to the XV. Two great architectonic patrons are identified: circular and rectangular, each one associated with different moments of regional prehistory- the first is linked to the Late Intermediate Period and the second to the Late Horizon Period or Horizon Inca. A spatial distribution of both patterns can be identified and it gives form to the use of productive space. Both situations- architectural patterns and use of the space -constitute what we refer to in this work like settlements patterns
\end{abstract}

Key words - Settlement patterns, X to the XV centuries, Precordillera de Arica - Chile, South Andes

\section{GENERALIDADES}

Como precordillera de Arica, consideramos en el presente trabajo al segmento de la vertiente occidental de la Cordillera de los Andes ubicado entre las coordenadas (UTM) $7860000 \mathrm{~N}$ y $8020000 \mathrm{~N}$, con una altura promedio de 3600 msnm¹. Su geomorfología está definida por una serie de pequeños valles que con dirección Este-Oeste, alimentan cuatro grandes sistemas fluviales u hoyas hidrográficas: Lluta, Azapa, Codpa y Camarones. A lo largo de dicha zona se encuentra distribuido un conjunto de sitios arqueológicos, que conocidos comúnmente bajo el término genérico de los «pukaras de la sierra de Arica» (Dauelsberg, 1983), constituyen la base de datos de este trabajo².

El método utilizado sigue la tendencia de trabajos anteriores (Muñoz et al., 1987a; 1987b; 1997) en los cuales hemos centrado nuestra atención en el patrón arquitectónico o constructivo, de los diferentes poblados, específicamente en la planta de los recintos analizados. Siguiendo dicha línea, planteamos ahora obtener una visión global del área de estudio, intentando una aproximación a los patrones de asentamiento y uso del espacio en la precordillera de Arica, entre los siglos X y XV.

1 La zona en cuestión corresponde hoy en día a la provincia de Parinacota, Primera Región de Chile.

2 El trabajo de prospección y excavación incluye un conjunto de aproximadamente 30 sitos arqueológicos ubicados en la sierra ariqueña, con sus respectivos levantamientos topográficos. A estos hemos sumado el resultado de similares investigaciones realizadas por otros investigadores en la zona de estudio. 


\section{1. La cuestión temporal}

La temporalidad de los sitios arqueológicos que sirven de base a este análisis ha sido discutida con profundidad en artículos previos (Muñoz et al., 1987a; 1987b; 1988). En esta oportunidad, nos interesa resaltar que las dataciones absolutas obtenidas, más el análisis estilístico de los fragmentos recolectados, entrega un parámetro temporal de seis siglos de ocupación $(+/-1000$ - 1600 d. C.), lo que en términos de la periodificación crono-cultural del extremo norte de Chile, corresponde a los períodos Intermedio Tardío, Tardío y Colonial Temprano. En este trabajo nos haremos cargo del análisis de los patrones de asentamiento correspondientes a los dos primeros períodos mencionados.

\section{2. La cuestión cultural}

La investigación etnohistórica realizada en la precordillera de Arica nos permite ver que durante el siglo XVI existió un control político de la zona por parte de la etnia Caranga, cuyo origen debiera remontarse a épocas prehispánicas (Durston \& Hidalgo, 1999; Hidalgo, 1999; Hidalgo \& Durston, 1998; Rivière, 1982). La etnia Caranga corresponde a una de las grandes agrupaciones étnicas de habla aymara que habitaron y habitan el altiplano meridional a partir del siglo $X$ d. C. En la actualidad ocupan el espacio territorial inmediatamente al este de la frontera chileno-boliviana, en el altiplano de Bolivia, colindante con las provincias chilenas de Parinacota e Iquique.

Aunque los orígenes Caranga son aún inciertos, se sabe que este grupo étnico constituyó una formación política de gran alcance y complejidad que le ha valido la denominación de Jefatura o Señorío (Michell, 2000; Rivière, 1982) y, al igual que otras organizaciones políticas semejantes (Lupacas y Pacajes) habrían utilizado el control territorial de diversos pisos ecológicos, según el modelo de verticalidad, propuesto por J. Murra (1975).

Desde el punto de vista de la arqueología, durante la época del período Intermedio Tardío o preinca, la precordillera de Arica habría actuado como una especie de Taypi, donde se articuló la presencia de dos grandes núcleos poblacionales: las poblaciones altiplánicas por una parte y las poblaciones locales o de valles occidentales3. El tipo de articulación que allí se dio ha sido catalogado como de «Convivencia y conflicto» (Muñoz et al., 1987a; Muñoz \& Chacama, 1999). De convivencia, por tanto se han detectado rasgos significativos de ambas poblaciones, dispuestos de forma homogénea a lo largo de todos los sitios estudiados y, de conflicto, por la presencia de aldeas con carácter defensivo (Pucaras), ubicadas estratégicamente en lo alto de cerros en cada uno de los valles prospectados.

La coexistencia señalada ha sido concebida de diferentes maneras según el área de investigación y según diversos investigadores. Algunos ejemplos: un control de la sierra por parte de las poblaciones de valles occidentales sobre las altiplánicas en el Valle de Codpa (Muñoz et al., 1987b); una coexistencia simétrica en un mismo poblado en el Valle de Belén (Romero, 1999); una coexistencia simétrica en dos poblados distintos en una misma área en el Valle de Camarones (Niemeyer et al., 1972-1973). Lo anterior indica que si bien en términos generales la sierra ariqueña presenta durante el período Intermedio Tardío una visión transversal homogénea, esta se diluye cuando el análisis se sectoriza en valles específicos. En otras palabras, durante el período Intermedio Tardío, en la precordillera de Arica se llevó a cabo una relación intercultural de convivencia y conflicto entre poblaciones de valles occidentales y poblaciones altiplánicas. La forma de esta interacción pareciera haber tenido variantes entre las distintas áreas geográficas (valles) que componen esta zona.

3 Otros autores han sugerido la presencia de una tercera población, propia de la precordillera la cual habría sido el eje de articulación entre las poblaciones altiplánicas y la de valles costeros; esto sería una ocupación multiétnica en la sierra de Arica (cf. Romero, 1999; Santoro et al., 2000). 
Sobre la situación cultural anteriormente planteada, se impuso, durante el período Tardío, la presencia del Estado Inca, detectada ésta por dos rasgos culturales distintivos: cerámica asociada a la expansión incaica y, sobre todo, por una arquitectura que, guardando la proporción con la arquitectura de los grandes centros incaicos, revela sin lugar a dudas la presencia del Estado en la zona. El estudio de la red de asentamientos Inca en la precordillera de Arica, ha proporcionado una primera mirada al tipo de administración e interacción que el Estado tuvo con y sobre las poblaciones que ocupaban la zona en estudio y cuya hipótesis más aceptada continúa siendo la de A. Llagostera, quien planteó un dominio indirecto de la vertiente occidental de los Andes vía poblaciones altiplánicas (Llagostera, 1976), hipótesis a la cual se han sumado otros autores (cf. Hidalgo \& Santoro, 2001; Muñoz et al., 1987a; 1987b; Niemeyer \& Shiappacasse, 1988; Shiappacasse \& Niemeyer, 1997; 2002). En lo específico se ha señalado que la presencia Inca en la zona tuvo un carácter político, administrativo y económico (Schiapacasse \& Niemeyer, 1997), siendo uno de sus objetivos el brindar apoyo logístico a las rutas que conducen a diversas zonas de interés económico (Niemeyer \& Shiapacasse, 1988: 142) con algunos centros administrativos locales como Saguara en la cuenca de Camarones (Schiapacasse \& Niemeyer, 2002: 79-82) y Zapahuira en la cuenca de Azapa (Muñoz et al., 1997: 135) en lo económico, la presencia Inca se orientaría al control pecuario y de bofedales en la cuenca del salar de Surire, del lago Chungara y Caquena entre otros (Aldunate, 2001a; Niemeyer \& Schiappacsse, 1988; Muñoz \& Chacama, 1993; Romero \& Briones, 1999) y hacia una explotación agraria en los valles y de recursos marinos en la costa (Aldunate, 2001a; Niemeyer \& Schiappacsse, 1988; Santoro et al., 2000).

\section{EL PATRÓN ARQUITECTÓNICO}

A fines de la década de 1990, nuestras investigaciones en la sierra ariqueña nos llevaron a plantear dos tipos de patrones arquitectónicos bien definidos. Uno de composición colmenar, con recintos circulares aglutinados, ubicado en las laderas o cima de los cerros y que denomináramos Patrón Circular. El otro, de base rectangular, ubicado en la periferia de los sitios de Patrón Circular o aislado de éstos, que denomináramos Patrón Rectangular (Muñoz et al., 1997). A continuación se presenta un resumen de la caracterización que hiciéramos de los patrones arquitectónicos señalados.

\section{1. El Patrón Circular}

En términos culturales y temporales, el Patrón Circular se asocia con la ocupación de las poblaciones locales, las que interactuaron en un mismo espacio doméstico-habitacional con poblaciones cuyo núcleo poblacional se encuentra en el piso altiplánico inmediatamente colindante a la precordillera de Arica, especialmente con grupos Caranga. Ambas poblaciones, la de valles occidentales y la altiplánica, fueron definidas a través de la presencia de estilos cerámicos representativos.

Por su parte, los sitios identificados bajo el Patrón Circular según ciertas características constructivas y, especialmente, según su lugar de emplazamiento, fueron denominados como aldeas o como pucaras ${ }^{4}$.

\section{1. 1. Las aldeas}

Corresponden a sitios con estructuras de planta circular de diversos diámetros, construidos con una o dos hiladas de piedras. Su característica principal es su emplazamiento en lugares aledaños a la ladera de un cerro, o en la ladera misma.

Los recintos de planta circular están hechos de mampostería simple, generalmente sin uso de aglomerante en la unión de las piedras. Cuando el asentamiento se encuentra ubicado en la

\footnotetext{
${ }^{4}$ Pucara, palabra aymara que significa castillo, fortaleza (Bertonio, 1984 [1612], II: 275).
} 
ladera de los cerros, la porción del muro más distante a esta presenta mayores proporciones que aquella porción adosada a la ladera, actuando a la vez como muro del recinto y como muro contenedor del talud de la ladera (fig. 1a). Del mismo modo, mientras más abrupta la pendiente, los recintos tienden a tomar formas más elípticas, esto como una respuesta de adecuación a la disponibilidad del terreno. Los recintos circulares, pueden presentar diversos rangos de diámetro y estar constituidos por una o dos hiladas de piedras. Aquellos que presentan dos hiladas de piedra, generalmentepresentan un relleno interior constituido por piedras de menor tamaño y barro, en cuyo caso, los muros pueden llegar a tener entre 80 y $90 \mathrm{~cm}$ de espesor. Los muros simples de una hilada presentan mayor variedad en su espesor, una gran parte de los ejemplos cuantificados tiene sus bases constituidas por grandes bloques que pueden superar el metro de espesor, disminuyendo a medida que aumenta la altura del muro (fig. 2). Un cruce de la información obtenida: diámetro del recinto vs. hiladas constructivas, entregó las siguientes tendencias (tabla 1).
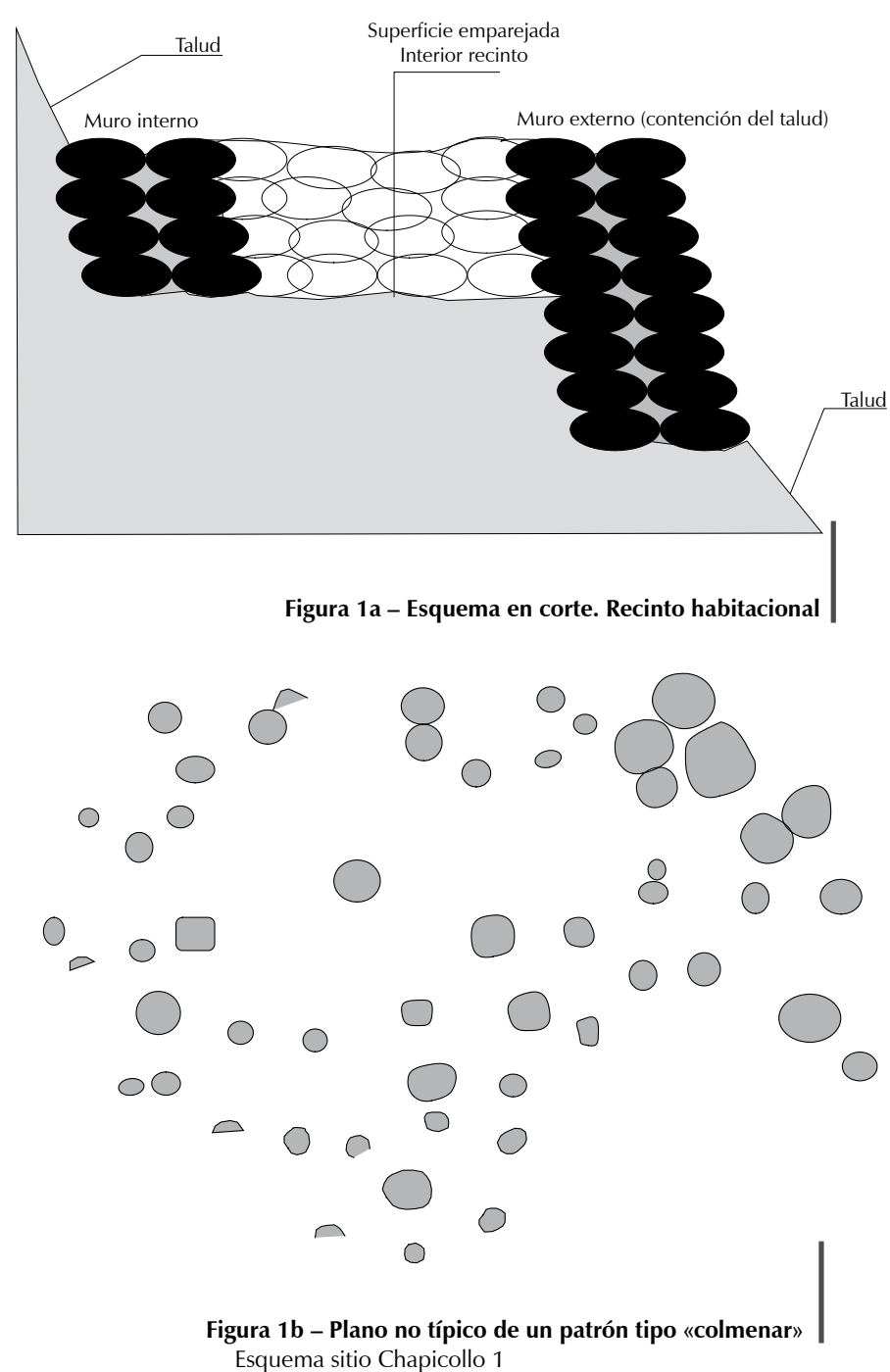

Tabla 1 - Diámetro del recinto, hiladas constructivas y función

\begin{tabular}{|c|c|c|}
\hline Rango de $\varnothing$ del recinto & $\mathbf{N}^{\circ}$ de hiladas constructivas & Función (tendencia) \\
\hline $1-1,5 \mathrm{~m}$ & Una o dos hiladas & Depósito o sili \\
\hline $8-15 \mathrm{~m}$ & Una hilada & Corral \\
\hline $2-5 \mathrm{~m}$ & Dos hiladas & Recinto habitacional \\
\hline
\end{tabular}

Algunos rasgos constructivos particulares que presentan los recintos circulares, son los vanos. La mayoría de los recintos de doble hilada con y sin relleno interior, especialmente aquellos mayores a $3 \mathrm{~m}$ de diámetro, denotan aberturas que habrían constituido vanos de acceso; estas tienen un 


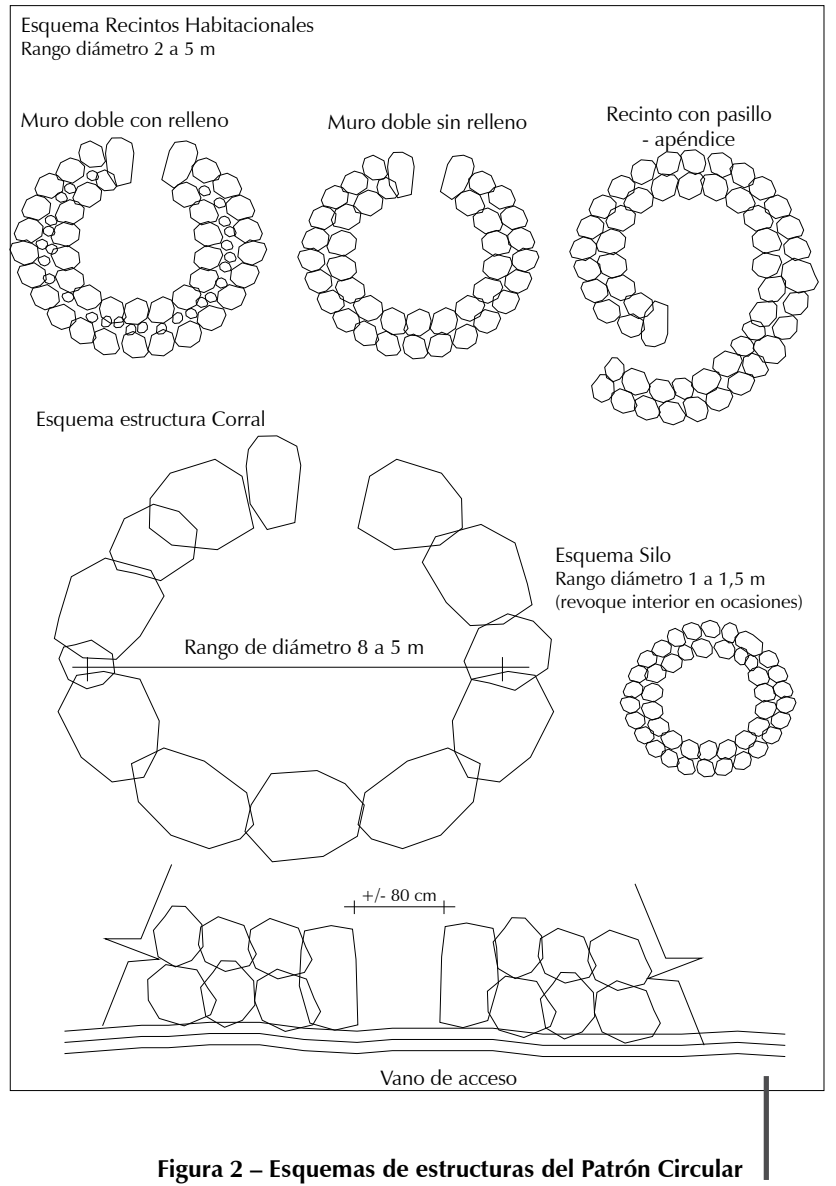

promedio de $60 \mathrm{~cm}$ de ancho y están delimitadas por piedras mayores que las del resto del muro, con esquinas bien definidas (fig. 2). Curiosamente, en todos los poblados estudiados, no hemos detectado la presencia de un dintel que corone estos vanos, lo que nos hace suponer que este elemento arquitectural no fue constitutivo del Patrón Circular.

Otros rasgos particulares de este patrón, aunque de mucho menor recurrencia, son los denominados pasillos-apéndices 5 . Estos se presentan como una prolongación de una parte del círculo perimetral, que nace a partir del vano de acceso (fig. 2). Su función podría estar directamente vinculada con la protección del recinto contra el desplazamiento de aguas de lluvia hacia su interior. Por último, se han detectado también situaciones de revoque (recubrimientos de barro) en el interior de recintos con un diámetro menor a $1,5 \mathrm{~m}$, lo que estaría estrechamente vinculado al tratamiento de silos de almacenaje (fig. 2).

Respecto al plano general que las aldeas presentan, este puede ser caracterizado como una formación «colmenar» (fig. 1b); esta se compone de un conjunto de recintos circulares distribuidos sobre el terreno sin una planificación aparente, los que pueden estar aislados o nucleados (dos o más recintos), a veces compartiendo parte de un mismo muro. No obstante el aparente «desorden» de este tipo de patrón, la mayoría de estas aldeas presentan espacios bastante definidos y diferenciados. Así, en ellas se puede distinguir un espacio doméstico concentrado, un sector donde se ubican estructuras para almacenaje y un sector para entierros; los dos últimos sectores se ubican generalmente en la periferia o en los extremos del núcleo habitacional. Por último, hay que considerar los espacios abiertos (a veces delimitados por muros bajos) comúnmente denominados «plaza» que se encuentran en un extremo o insertos en el sitio mismo, a las que se les ha atribuido funciones de intercambio de bienes y/o ceremoniales.

\section{1. 2. Los pucaras}

Los pucaras o aldeas defensivas, en términos constructivos, presentan las mismas características que las aldeas. Tienen recintos habitacionales similares a los descritos previamente y utilizan las mismas características constructivas. Del mismo modo, se aprecian en ellos la presencia de estructuras menores clasificadas como silos; no se percibe la presencia de recintos tipo corral.

5 Este rasgo solo ha sido detectado en los sitios Chapicollo 1 y Cobija 1 y algunos recintos de Huaihuarani. 
Se diferencian de las aldeas por su emplazamiento «estratégico» en la cima de un cerro o en sectores escarpados. Poseen una o dos corridas de grandes piedras a manera de un muro perimetral, el que habría cumplido funciones defensivas. En varios de ellos, existe un espacio libre detrás del muro defensivo o entre ellos cuando existe más de uno. En el caso que los pucaras se encuentren rodeados por laderas escarpadas, el muro defensivo se encuentra en el lugar de más fácil acceso al sitio. Dependiendo su ubicación pueden ser caracterizados como:

Pukaras de media altura Cuando se encuentran en conos de deyección o en salientes de las laderas de los valles, a una altura menor que la cumbre.

Pukaras de cumbre Cuando se encuentran en la cima de un cerro isla.

Aldea y pucara En tales casos el sector de pucara (sector defensivo) se encuentra contiguo a la aldea, ubicándose en la zona más escarpada de esta (fig. 3).
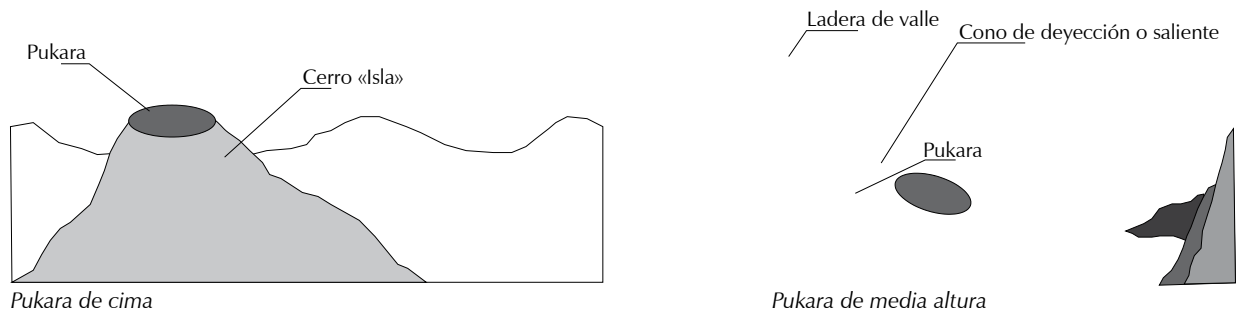

Pukara de media altura
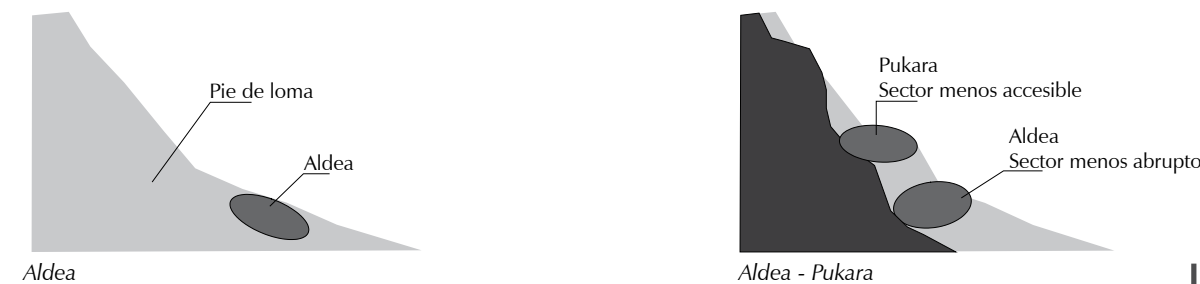

Figura 3 - Clasificación de los pukaras y aldeas según su ubicación espacial

\section{1. 3. Distribución espacial del Patrón Circular}

En ocasiones anteriores hemos caracterizado y definido en forma independiente el patrón arquitectónico de diversas áreas y sitios estudiados (Muñoz et al., 1987a; 1987b; 1997; Muñoz \& Chacama, 1993; 1997). En esta ocasión intentaremos constituir un panorama general de la sierra de Arica, incorporando al análisis propuesto un conjunto de sitios estudiados a partir del año 2000, como también un conjunto de sitios estudiados por otros equipos de investigación, que se ubican en las cabeceras de las cuencas hidrográficas involucradas en el área en estudio6.

A continuación se presentan cuatro tablas que resumen el Patrón Circular y su distribución espacial en la precordillera de Arica. Estas corresponden a sitios arqueológicos ubicados en las cabeceras de las cuatro cuencas hidrográficas de importancia: Lluta, Azapa, Codpa y Camarones. Las tablas están acompañadas por un plano esquemático que muestra la ubicación de los sitios indicados (fig. 4).

6 Estas cabeceras de cuenca corresponden al Valle de Lluta, estudiado sistemáticamente por C. Santoro y colaboradores, y el valle de Camarones investigado durante décadas por H. Niemeyer \& V. Schiappacasse. 
Tabla 2 - Cuenca del valle de Lluta (cabecera)

\begin{tabular}{|c|c|c|l|}
\hline SITIO & SECTOR & TIPO SITIO & \multicolumn{1}{c|}{ REFERENCIA } \\
\hline Coca & Socoroma & Aldea & Santoro et al., 1987 \\
\hline Calacruz & Socoroma & Pucara media altura & Muñoz \& Chacama, 2005 \\
\hline Cachuchatiza & Socoroma & Pucara & $\begin{array}{l}\text { Dauelsberg, 1995 [1959]*, Muñoz \& } \\
\text { Chacama,2005 }\end{array}$ \\
\hline
\end{tabular}

* Levantamiento topográfico

Tabla 3 - Cuenca hidrográfica del valle de Azapa (cabecera)

\begin{tabular}{|c|c|c|l|}
\hline SITIO & SECTOR & TIPO SITIO & \multicolumn{1}{|c|}{ REFERENCIA } \\
\hline Pubriza & Valle Azapa & Poblado & Muñoz \& Chacama, 1999; Muñoz \& Santos, 2000 \\
\hline Ancopachane & Belén & Poblado & Dauelsberg, 1983 \\
\hline Huaihuarani & Belén & Aldea/Pucara & Dauelsberg, 1983; Muñoz et al., 1997; Romero, 1999 \\
\hline Incahullo & Belén & Poblado & Dauelsberg, 1983 \\
\hline Trigalpampa & Belén & Poblado & Dauelsberg, 1983 \\
\hline Pujone & Chapiquiña & Aldea/Pucara & Muñoz \& Chacama, 2005 \\
\hline Laco Alto & Chapiquiña & Poblado & Muñoz \& Chacama, 1999 \\
\hline Caillama & Chapiquiña & Pukara & Romero, 1999; 2002; Muñoz \& Chacama, 2005 \\
\hline Lupica & Lupica & Aldea/Pucara & Muñoz et al., 1997 \\
\hline Saxamar & Tignamar & Poblado & Muñoz et al., 1997 \\
\hline Charcollo & Tignamar & Poblado & Dauelsberg, 1995 [1959]; Muñoz \& Chacama, 2005 \\
\hline Chapicollo 1 & Zapahuira & Poblado & Muñoz et al., 1987a \\
\hline Chapicollo 2 & Zapahuira & Pukara de cumbre & Muñoz et al., 1987a \\
\hline Huaycuta & Zapahuira & Pukara de cumbre & Muñoz et al., 1987a \\
\hline
\end{tabular}

Tabla 4 - Cuenca hidrográfica del valle de Codpa (cabecera)

\begin{tabular}{|c|c|c|c|}
\hline SITIO & SECTOR & TIPO SITIO & REFERENCIA \\
\hline Incauta & Incauta & Aldea/Pucara & Muñoz et al., 1987b \\
\hline Vila Vila 1 & Vila Vila & Pucara de media altura & Muñoz et al., 1987b \\
\hline Vila Vila 2 & Vila Vila & Pucara de media altura & Muñoz et al., 1987b \\
\hline Molle Grande 1 & Molle Grande & Pucara de media altura & Muñoz et al.,1987b \\
\hline Cobija 1 & Cobija & Pucara de cumbre & Muñoz et al., 1997 \\
\hline Cobija 2 & Cobija & Aldea & Muñoz et al., 1997 \\
\hline
\end{tabular}

Tabla 5 - Cuenca hidrográfica del valle de Camarones (cabecera)

\begin{tabular}{|c|c|c|l|}
\hline SITIO & SECTOR & TIPO SITIO & \multicolumn{1}{|c|}{ REFERENCIA } \\
\hline Sabaipugro & Camarones & Pucara de altura & Niemeyer et al., 1972-1973 \\
\hline Chibaljaya 1 & Camarones & Aldea & Niemeyer et al., 1972-1973 \\
\hline Chibaljaya 2 & Camarones & Pucara de altura & Niemeyer et al., 1972-1973 \\
\hline Quiguatama 2 & Camarones & Aldea & Niemeyer et al., 1972-1973 \\
\hline Saguara 3 & Saguara & Aldea & Niemeyer et al., 1972-1973 \\
\hline Miñita 2 & Miñita & Pucara de altura & Muñoz et al., 1997; Muñoz \& Santos, 1998 \\
\hline Miñita 3 & Miñita & aldea & Muñoz et al., 1997; Muñoz \& Santos 1998 \\
\hline Miñita 4 & Miñita & Aldea & Muñoz et al., 1997; Muñoz \& Santos 1998 \\
\hline
\end{tabular}


Patrón de asentamiento y uso del espacio. Precordillera de Arica, extremo norte de Chile, siglos X-XV

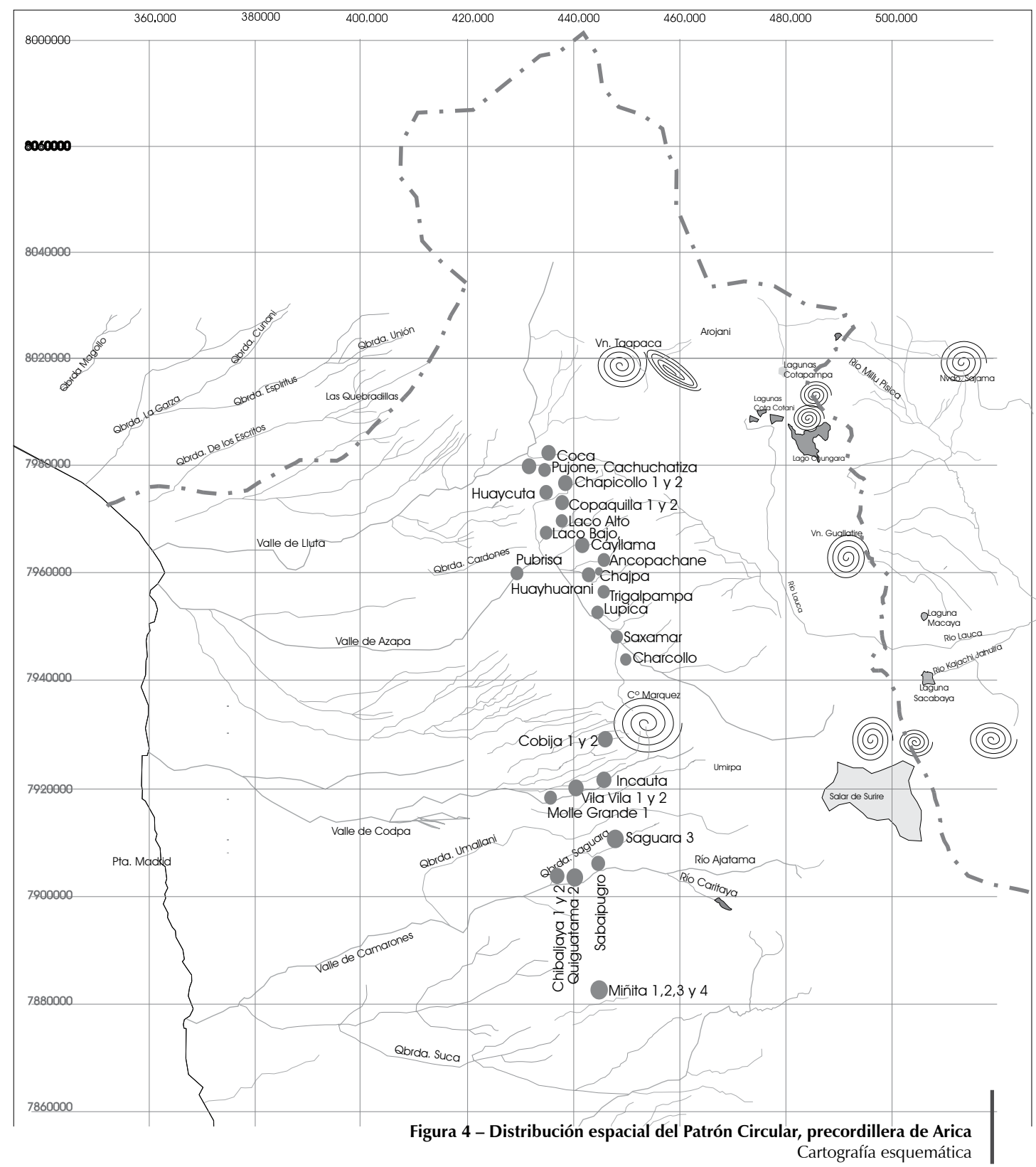




\section{2. El Patrón Rectangular}

En términos culturales y temporales, el Patrón Rectangular está directamente asociado a la presencia Inca en la zona (Aldunate, 2001a; Muñoz et al., 1987a; 1987b; 1997; Niemeyer et al., 1972-1973; Niemeyer \& Schiappacasse, 1988). Constructivamente se caracterizan por ser recintos cuadrangulares o rectangulares cuyas esquinas están definidas por ángulos rectos. Este indicador de esquina, aunque a primera vista simple, define en gran medida este patrón y lo diferencia de otros recintos que, también a primera vista, podrían calificarse como rectangulares, pero que una mirada más acuciosa caracteriza como una variante «más rectangular» del Patrón Circular (i. e. Vila Vila 2). La esquina en ángulo recto y la presencia de dintel en vanos de puertas y «ventanas», son algunas de las características constructivas del Patrón Rectangular que lo diferencian del Patrón Circular.

Este patrón está principalmente asociado a construcciones con funciones específicas, inherentes a la administración Inca en la zona. En términos funcionales podríamos visualizar las instalaciones del Patrón Rectangular, bajo el concepto de Tambo Inca expuesto por Hyslop (1992). No obstante, según dicho autor, la arquitectura y tamaño de los tampus es sumamente variada y probablemente la única característica que les sea común; es su asociación con la red vial Inka o Qhapaqñan (camino real). Estas instalaciones, además de su condición de centros de alojamiento y almacenaje, destinados a servir de bastimento a funcionarios y al ejército del Estado, habrían cumplido funciones político-administrativas y de ceremonial público, aspectos indisolubles en la política de expansión incaica.

\section{2. 1. El camino real en la precordillera de Arica}

Antes de proseguir con nuestro análisis del Patrón Rectangular, pensamos que es necesario hacer un breve resumen de lo que se ha considerado como un segmento del Qapaqñan en la precordillera ariqueña. No nos motiva en esta instancia hacer una discusión sobre las características constructivas de este camino ni mucho menos si se trata o no del Camino Real o de rutas previas, reutilizadas por el incario. Nuestra visión recoge más bien análisis previos sobre este tramo del camino Inca7, siendo nuestro punto de interés poner en relevancia que esta ruta se encuentra directamente vinculada al conjunto de aldeas y pucaras ya descritas y al conjunto de instalaciones caracterizadas bajo el título de Patrón Rectangular. Esta vinculación puede consistir en pasar directamente por determinadas instalaciones o algunos cientos de metros de distancia.

Las áreas que este sistema vial involucra, de norte a sur y a una cota aproximada de $3600 \mathrm{msnm}$, son: Socoroma (Coca, Calacruz, Cachuchatiza)8; Zapahuira (Chapicollo 1 y 2, Zapahuira 1 y 2 , Huaicuta, Copaquilla 1 y 2); Chapiquiña (Lacco Alto, Pujone, Caillama), Belén (Ancopachane, Chajpa, Trigalpampa, Incahullo, Huahuarani); Lupica (Lupica), Saxamar (Saxamar); Ticnamar (Charcollo, Tangane); Cobija (Cobija 1 y 2); Codpa (Incauta); Saguara (Saguara I, II, III y IV). Paralelamente a este eje vial norte-sur, existen sistemas secundarios que bajan a lo largo de los valles uniendo sus cabeceras con la costa.

7 Para el tramo Socoroma-Zapahuira ver Santoro, 1983; para el tramo Zapahuira-Miñita ver Muñoz \& Briones, 1998. Para aspectos específicos del sector de Belén ver Dauelsberg, 1983 y para el valle de Camarones ver Niemeyer \& Schiappacasse, 1988 y Schiappacasse \& Niemeyer, 2002.

8 Los nombres indicados para las áreas corresponden a los nombres de diferentes valles y que aún cuentan con población estable. Los nombres entre paréntesis corresponden a sitios arqueológicos comprendidos en las áreas o valles ya señalados. 


\section{2. 2. Distribución espacial del Patrón Rectangular}

A continuación examinaremos las diferentes instalaciones que conforman el Patrón Rectangular en la precordillera de Arica. Para tal efecto revisaremos las cabeceras de las cuatro cuencas hidrográficas que hemos analizado, sus diversos sectores y los sitios arqueológicos ubicados en cada uno de ellos.

La tabla 6 que mostramos a continuación nos entrega un panorama general de las instalaciones con Patrón Rectangular asociadas a la presencia Inca en la zona. La función o tipo de instalación definida se obtuvo aplicando algunas categorías propuestas por Hyslop respecto al sistema de tampus (Hyslop, 1992), lo que diversos investigadores han señalado para cada uno de estos sitios y nuestra visión del problema la que tiene su base en el orden de cosas con el cual fue concebido el estado Inca, el cual fue replicado en las regiones incorporadas bajo el dominio del Tawantinsuyu9.

Encontramos un punto de partida en T. Zuidema quien, en su búsqueda sobre la organización social del estado Inca, encontró en el sistema de ceques del Cuzco un punto de partida ideal para la comprensión de dicho sistema de organización. El sistema de ceques no solo habría funcionado como un calendario ceremonial sino que además su implementación involucraba la participación de los diferentes órdenes sociales existentes en la capital del imperio. Zuidema visualizó además que este sistema fue replicado en las distintas instancias territoriales que ocupó el estado Inca y cuyas reminiscencias aún son perceptibles en comunidades rurales del Perú contemporáneo (Zuidema 1995). Del planteamiento de Zuidema, nos interesa rescatar la idea de un orden central que fue replicado en las distintas instancias regionales involucradas bajo el Estado.

Siguiendo una lógica similar, el sistema de asentamientos y planificación Inca replicó en las distintas regiones incorporadas al Estado, un patrón ideológico-arquitectónico conceptualmente más o menos similar al encontrado en el Cuzco. El Estado tuvo al respecto una suerte de plan maestro consistente en erigir similares tipos de edificios en los territorios conquistados, articulados éstos por una extensa red vial que abarcaba todo el territorio. Esta arquitectura cuya finalidad última era facilitar la administración del Estado, ya sea por medio de acciones logísticas o de actos político-ceremoniales, tuvo un patrón constructivo que remitió constantemente a la estructura epónima planificada y construida en la capital del imperio10.

Una segunda idea necesaria de tener en cuenta son las características de los valles de la precordillera de Arica, especialmente su aspecto demográfico. Si bien es cierto que la amplitud de campos de cultivo y el complejo sistema de irrigación en el cual se insertaron, tanto las aldeas agrícolas como luego la administración Inca, nos puede inducir a pensar en una gran población prehispánica, el hecho cierto es que esta población aparentemente nunca habría superado las cinco mil personas11.

Nuestro parecer es que el concepto estatal de replicar las instalaciones del centro simbólico, Cuzco, en las diferentes regiones incorporadas bajo su administración, estuvo, en cierta medida, parametrada por las características del territorio ocupado. Esta adaptación local del patrón incaico estaría entonces directamente relacionada con la importancia relativa de cada valle, en este caso los de la precordillera de Arica.

9 Un análisis pormenorizado de cada una de las estructuras reseñadas en la tabla 6 se encuentra en Muñoz \& Chacama, 2005.

10 Para una mejor comprensión de los patrones de asentamiento Inca y su arquitectura se puede consultar la obra de Gasparini \& Margolies, 1980 e Hyslop, 1990.

11 La cifra entregada es solo un referente general, para mayores detalles puede consultarse Hidalgo, 1978; Hidalgo et al., 2004 y Trelles, 1991. 
Tabla 6 - Resumen del Patrón Rectangular (ver figura 5)

\begin{tabular}{|c|c|c|c|c|}
\hline CUENCA & SECTOR & SITIO & TIPO o FUNCIÓN & REFERENCIA \\
\hline \multirow{7}{*}{ Azapa } & \multirow{2}{*}{ Zapahuira } & Zapahuira 1 & \multirow{2}{*}{$\begin{array}{l}\text { Centro administrativo } \\
\text { ¿provincial? } \\
\text { (qollcas, kanchas y red } \\
\text { vial) }\end{array}$} & $\begin{array}{l}\text { Muñoz et al., 1987a; } \\
\text { Chacama et al., } 1989\end{array}$ \\
\hline & & Zapahuira 2 & & Muñoz et al., 1987b \\
\hline & Pubrisa & Pubrisa & $\begin{array}{l}\text { Centro administrativo- } \\
\text { político y ceremonial } \\
\text { (edificio rectangular } \\
\text { con plaza y qollcas) }\end{array}$ & Muñoz \& Santos, 2000 \\
\hline & \multirow{3}{*}{ Belén } & Chajpa & Tampu - Chaskiwasi & Dauelsberg, 1983 \\
\hline & & Incahullo & $\begin{array}{l}\text { Centro administrativo- } \\
\text { político y ceremonial } \\
\text { (edificios rectangulares } \\
\text { con plaza, qollqas, } \\
\text { edificio circular con } \\
\text { hornacinas) } \\
\end{array}$ & Dauelsberg, 1983 \\
\hline & & Huaihuarani & $\begin{array}{l}\text { Tampu } \\
\text { (ikancha?) }\end{array}$ & $\begin{array}{l}\text { Dauelsberg, 1983; Muñoz } \\
\text { et al., 1987a; Romero, } \\
\text { 1999 }\end{array}$ \\
\hline & Chapiquiña & Lacco alto & Tampu - Chaskiwasi & Muñoz \& Chacama, 2005 \\
\hline \multirow[t]{3}{*}{ Codpa } & \multirow[t]{2}{*}{ Codpa } & Incauta & $\begin{array}{l}\text { Centro administrativo- } \\
\text { político y ceremonial } \\
\text { (edificios rectangulares } \\
\text { con plaza) }\end{array}$ & Muñoz et al., 1987b \\
\hline & & Molle Grande 2 & Tampu & Muñoz et al., 1987b \\
\hline & Cobija & Cobija 2 & Tampu & Muñoz \& Chacama, 2005 \\
\hline \multirow[t]{2}{*}{ Camarones } & Sahuara & Sahuara & $\begin{array}{l}\text { Centro administrativo- } \\
\text { político y ceremonial } \\
\text { tampu y ushnu }\end{array}$ & $\begin{array}{l}\text { Niemeyer et al., 1972-1973; } \\
\text { Niemeyer \& Schiappacasse, } \\
\text { 1988; Schiappacasse \& } \\
\text { Niemeyer, } 2002\end{array}$ \\
\hline & Camarones & $\begin{array}{l}\text { San Antonio de } \\
\text { Turuguire } 3\end{array}$ & $\begin{array}{l}\text { Tampu } \\
\text { Kancha }\end{array}$ & $\begin{array}{l}\text { Niemeyer \& } \\
\text { Schiappacasse, } 1988\end{array}$ \\
\hline \multirow{3}{*}{ Altiplano } & Tacora & Ankara & $\begin{array}{l}\text { Tampu } \\
\text { ¿Kanchas? }\end{array}$ & $\begin{array}{l}\text { Muñoz \& Chacama, 1993; } \\
\text { 1999; Muñoz et al., } 1997\end{array}$ \\
\hline & Caquena & Pisarata & Tampu & $\begin{array}{l}\text { Muñoz \& Chacama, 1993, } \\
\text { 1999; Muñoz et al., } 1997\end{array}$ \\
\hline & $\begin{array}{l}\text { Lago } \\
\text { Chungara }\end{array}$ & Chungara ${ }^{12}$ & $\begin{array}{l}\text { Centro político } \\
\text { ceremonial } \\
\text { (edificios rectangulares } \\
\text { con plaza y ushnu) }\end{array}$ & $\begin{array}{l}\text { Chacón \& Orellana 1979; } \\
\text { Muñoz et al., 1997; } \\
\text { Aldunate, 2001b }\end{array}$ \\
\hline
\end{tabular}

12 No obstante lo señalado, existen evidencias que señalarían que el tambo de Chungara pertenece a una época más tardía (Colonial temprano). Una datación TI de 1695 d. C. así lo confirmaría (Muñoz et al., 1997). Por otra parte una prospección realizada por C. Santoro, junto a uno de los muros del tambo, entregó evidencias de cerámica esmaltada y vidrio hasta el nivel más profundo (Santoro com. pers., 2004). 
Patrón de asentamiento y uso del espacio. Precordillera de Arica, extremo norte de Chile, siglos X-XV

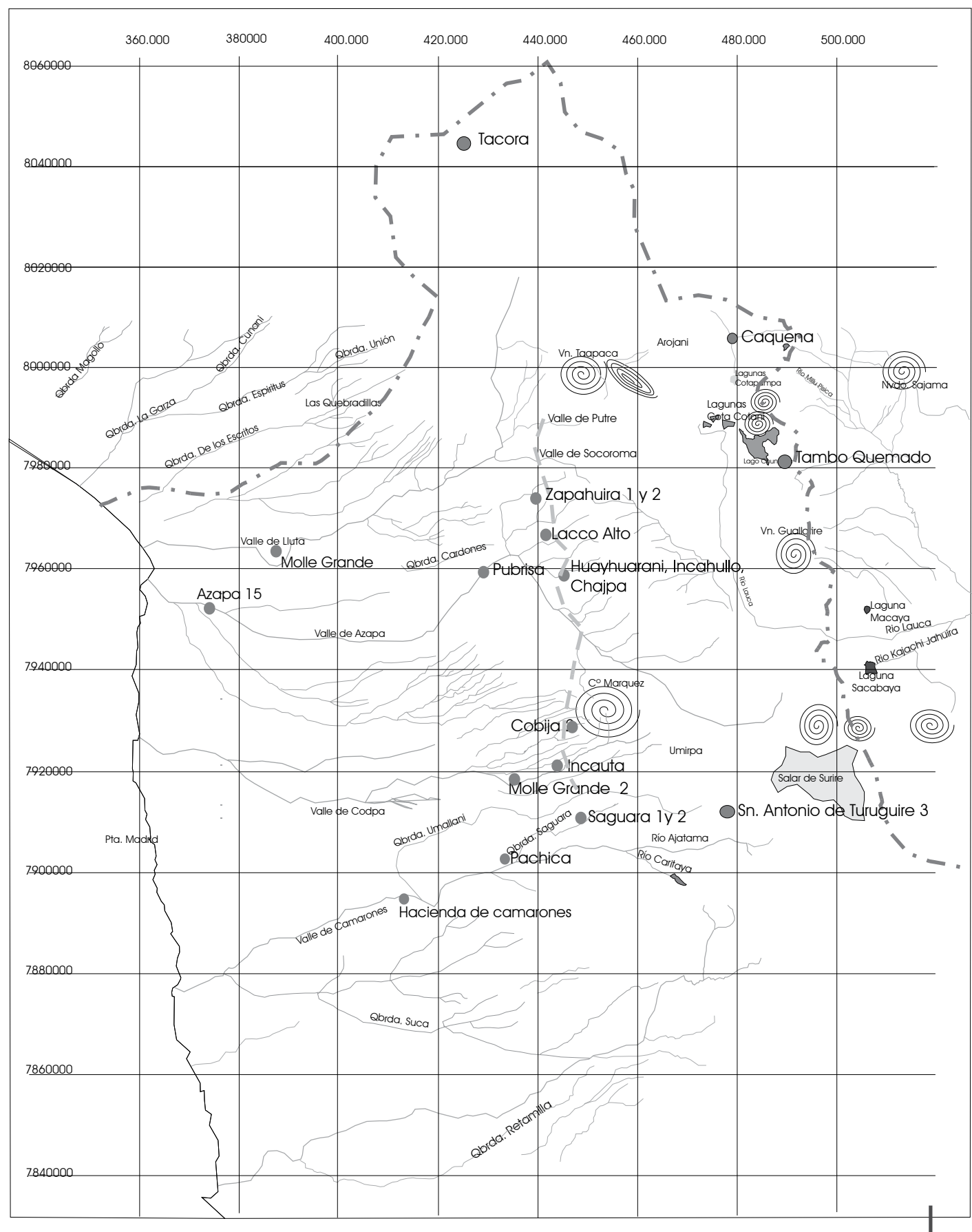

Figura 5 - Distribución espacial Patrón Rectangular, precordillera de Arica. Cartografía esquemática $----=$ Camino Inca prospectado 
Si bien las funciones propuestas en la tabla precedente no están completamente esclarecidas y la consideramos aquí como una aproximación tentativa, éstas nos entregan una primera aproximación a lo que denominamos como una red de instalaciones incaicas caracterizadas por un Patrón Rectangular13. La figura 6 presenta un esquema de planta de cada una de estas instalaciones.

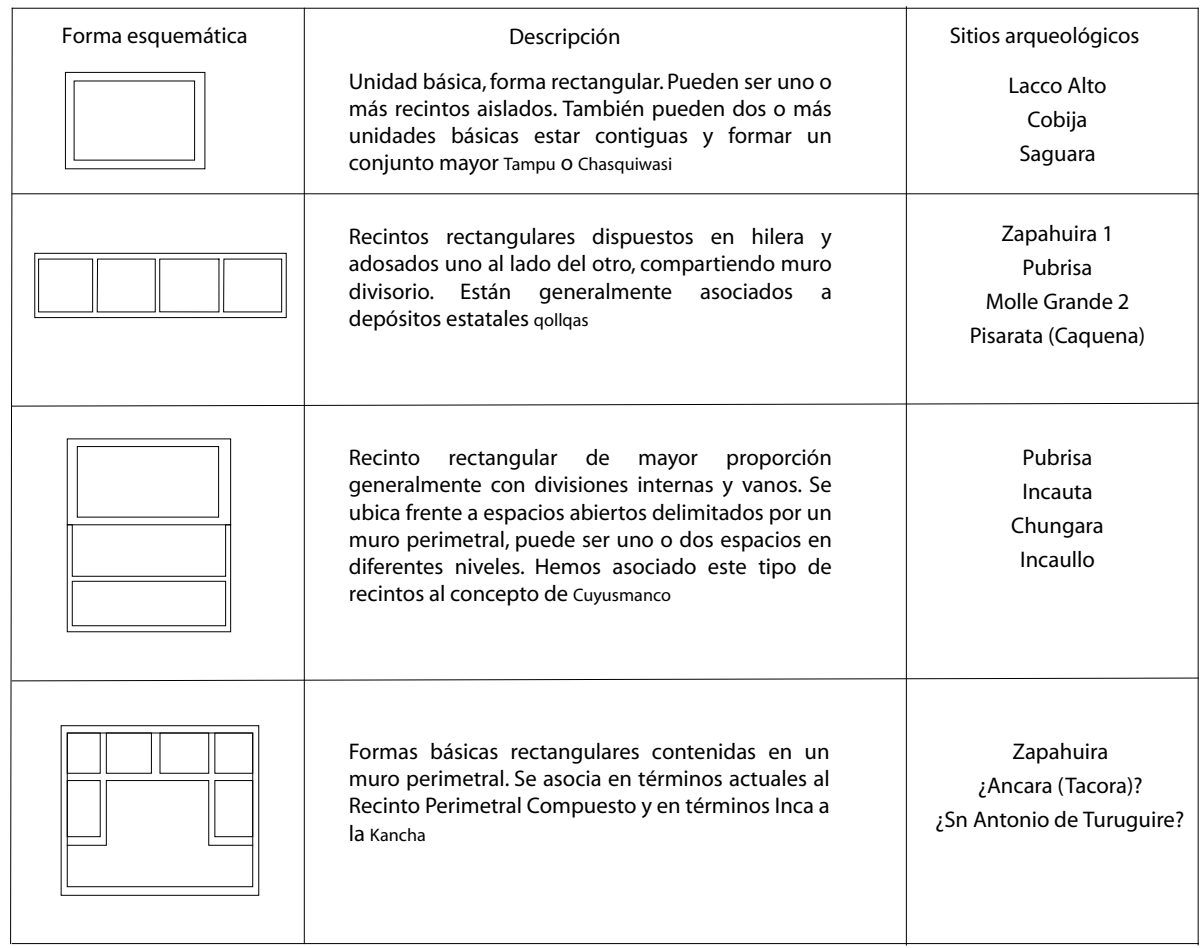

Otras formas asociadas al Patrón Rectangular y al incario

\begin{tabular}{|c|c|c|}
\hline & $\begin{array}{l}\text { Edificios circulares con hornacinas en su interior. } \\
\text { Asociado al concepto de Sunturhuasi }\end{array}$ & Incahullo \\
\hline & \begin{tabular}{|c|c|} 
Plataformas escalonadas asociadas al concepto de \\
Ushnu
\end{tabular} & $\begin{array}{c}\text { Saguara } \\
\text { Chungara }\end{array}$ \\
\hline \\
\hline
\end{tabular}

Aproximación a su función según conceptos del Incanato y sitios arqueológicos asociados

13 Es necesario señalar que si bien el marco geográfico de interés en este trabajo lo constituye la precordillera de Arica, especialmente las cabeceras de valles, hemos incorporado en la tabla 6 tres instalaciones de Patrón Rectangular que se encuentran en el altiplano en una cota aproximada a los $4500 \mathrm{msnm}$, obteniendo de esta manera una visión un tanto más global de esta red de instalaciones. 


\section{PATRÓN DE ASENTAMIENTO Y USO DEL ESPACIO EN LA PRECORDILLERA DE ARICA}

\section{1. El Intermedio Tardío, aldeas agrícolas y aldeas defensivas}

Durante el período Intermedio Tardío, ca. 1000 a 1400 d. C., el patrón de asentamiento de la sierra de Arica está compuesto exclusivamente por lo que denominamos Patrón Circular. Este presenta una organización espacial dispersa en la mayoría de los pequeños valles que conforman las cuatro cuencas hidrográficas analizadas y donde cada uno de estos valles cuenta a lo menos con una aldea y con la presencia de un pucara.

\section{1. 1. Las aldeas agrícolas}

Una de las características más relevantes de las denominadas aldeas, es que estas se encuentran insertas en medio de vastos complejos agrícolas, los que se caracterizan por un sistema de cultivos en terrazas o andenes de cultivo, ubicados en las laderas de los valles e irrigadas por una extensa red de canales primarios y secundarios. Los canales primarios recorren varias decenas de kilómetros desde su nacimiento en la parte alta de los valles, cubriendo toda la extensión de los campos agrícolas. Su función principal consiste en trasladar el agua a lo largo de todo el tramo del valle que sea necesario cubrir. Los segundos, de menor extensión, se desprenden de los primeros y tienen como función irrigar las distintas sementeras. En ocasiones, sobre todo en valles largos (i.e. Codpa), los canales primarios «unen» a su paso más de una aldea, situación que debió influir en los acuerdos políticos entre ellas. Del mismo modo, los canales secundarios, hasta el día de hoy son usados por turnos (mit'a de regadío), lo que involucra una organización social de la aldea en torno a la actividad agrícola y el uso del recurso agua, organización que se extiende a las obras destinadas a la manutención de este sistema. Este último aspecto, aunque puede ser considerado como un aspecto puramente tecnológico, implica un alto grado de organización social y también un complejo ritual en torno al trabajo de limpieza de los canales ${ }^{14}$ (Lagos et al., 1982).

Por su parte, las aldeas y sus componentes son un reflejo de esta actividad económica primaria. Estas, más allá de ser lugares para la vida doméstica con un conjunto de recintos habitacionales que constituyen el núcleo poblacional de la aldea, contienen también espacios y estructuras destinados al almacenaje de la producción agrícola así como también recintos destinados a albergar una cierta masa de camélidos (corrales), seguramente destinada al manejo de los productos agrícolas (traslado e intercambio) y también al consumo interno de éstos (carne y fibra).

Por todas las características señaladas en los párrafos anteriores, hemos definido a este conjunto de aldeas como «aldeas agrícolas», constituidas por recintos de planta circular con un plano de tipo colmenar, dispersas en los diversos valles de la Precordillera de Arica e insertas en medio de vastos campos de cultivos con terrazas agrícolas y sistemas de canales de irrigación.

\section{1. 2. Las aldeas defensivas, pucaras}

Intrínsicamente relacionadas con las aldeas agrícolas, existe un conjunto de sitios arqueológicos que por su posición estratégica — lugares abruptos de difícil acceso, o aislados en la cumbre de un cerro isla y rodeados por uno o más muros perimétricos-, han sido caratulados por la literatura especializada como aldeas defensivas o pucaras. Históricamente, estos han sido

14 En relación con los sistemas de regadío y la organización social en los Andes puede verse el trabajo de Zuidema, 1989 y para el norte de Chile, Socaire el trabajo de T. Barthel (1959), citado por Zuidema (1989). 
referidos en la documentación colonial como respuesta a una situación de conflicto que afectara al mundo andino previa a la expansión del estado Inca (Cf. Cieza de León, 1986 [1153-1554], II: 7; Pachacuti, 1993 [1613]: f.3v.; Guaman Poma, 1987 [1615]: 58-60).

Resumiendo lo hasta aquí expuesto, podemos decir que el período Intermedio Tardío en la precordillera de Arica está caracterizado por un patrón de asentamiento propio de una cultura eminentemente agrícola con una o más aldeas en cada pequeño valle. Paralelamente a las aldeas, existen en la región un conjunto de aldeas defensivas o pucaras que si bien no son un producto directo de la cultura agrícola imperante, sí son el resultado de las relaciones sociales especialmente políticas que afectaban al parecer gran parte del territorio antes del establecimiento y expansión del estado Inca. Así tenemos que durante el Intermedio Tardío el patrón de asentamiento y uso del espacio en la precordillera de Arica está definido en gran medida por el uso agrícola del suelo y el recurso hídrico y por las características conflictivas que afectaban la zona.

\section{2. El período Tardío, el Patrón Rectangular y la presencia Inca}

Antes de desarrollar este punto es necesario reafirmar que el Patrón Circular caracterizado para el período Intermedio Tardío no desaparece durante esta época, sino por el contrario, continúa durante todo el período Tardío e inclusive entrada la Colonia. Los cambios de importancia introducidos al Patrón Circular se producen solamente a partir de las Ordenanzas del virrey Toledo en la segunda mitad del siglo XV|15.

No obstante lo anterior, el énfasis que damos aquí al período Tardío, y he aquí la diferencia, es la presencia en la zona de un nuevo orden político y administrativo: el Incario. Este nuevo orden junto con todos los cambios que introdujo, trajo consigo un nuevo tipo de arquitectura que, como lo señaláramos previamente, introdujo algunos rasgos constructivos que lo distinguen formal y visualmente del Patrón Circular, siendo el principal la forma rectangular de sus plantas, por lo que denomináramos a este patrón arquitectónico como Patrón Rectangular. Por otra parte, y según señaláramos en la tabla 6, las diversas instalaciones Inca que conforman este patrón presentan una diversidad de funciones que, por una parte, responden a un orden de cosas preestablecido y, por otra, están en directa proporción con las características específicas de cada zona incorporada al Estado.

De acuerdo a lo señalado, una primera aproximación al uso del espacio del Patrón Rectangular o Inca nos presenta algunas tendencias que podríamos resumir como sigue:

- El patrón Rectangular-Inca se estableció en las cercanías de las aldeas agrícolas locales, ya sea en un extremo o periferia de $\operatorname{estas}^{16} \mathrm{o}$, en forma aislada, aunque siempre cercano a dichas aldeas ${ }^{17}$. La mayor cantidad de dichas instalaciones se encuentra en la cota del eje serrano de la red vial Inca o en sus inmediaciones. Otras se encuentran vinculadas a los ejes perpendiculares de esta red, que siguen el curso de los valles.

- Para cada cuenca o valle de importancia habría algún tipo de arquitectura que permitió postular una instalación político-administrativa y ceremonial que actuaría como centro administrativo o de control de dicha cuenca o valle: Zapahuira para el Valle de Lluta y de

15 Uno de los aspectos esenciales de las Ordenanzas del virrey Toledo guarda relación con las políticas de reducción de los naturales en «Pueblos de Indios». Su objetivo fue confinar en un único «gran» poblado a un conjunto de aldeas dispersas en los valles. Este nuevo patrón se caracterizó, en términos generales, por tener un plano tipo damero y recintos de planta rectangular.

16 Incauta, Cobija 2, Lacco, Huahuarani.

17 Zapahuira 1 y 2, Chajpa, Incaullo, Molle Grande 2. El único esquema diferente en la región la constituyen las instalaciones de Pubrisa, que se encuentran insertas en el medio de un poblado local pre-inca. Las instalaciones del Altiplano: Ankara, Pisarata, Chungara, escapan a esta norma y constituyen ejemplos aislados de la presencia de poblaciones locales. 
Azapa; Incahullo Valle de Belén; Incauta Valle de Codpa; Saguara Valle de Camarones. De estas, el conjunto de Zapahuira habría cumplido un papel mayor, posiblemente el de un centro administrativo provincial.

- Instalaciones distantes unas de otras podrían haber actuado como una sola unidad. Zapahuira y Pubrisa en la cabecera del valle de Azapa; Chajpa e Incahullo en Belén. Esto implica comprender al conjunto de estas instalaciones como una red cuyas diferentes partes actuarían en forma complementaria. Aunque no tenemos aún la certeza de una situación como la señalada, las relaciones espaciales que algunos sitios presentan entre sí, nos lleva a suponer un tipo de funcionamiento complementario.

- Existen evidencias de Chullpas en casi todos los sectores catalogados como centros administrativos. Esto evidenciaría una relación Inca-Señores Altiplánicos (presumiblemente Caranga) en el control y manejo de estos centros y las poblaciones allí establecidas.

Los puntos señalados anteriormente entregan un panorama general de lo que fue el uso del espacio por parte del Incario en la precordillera de Arica, evidenciado este a la luz de nuestro análisis del Patrón Rectangular. Sabemos que muchas de la sugerencias entregadas necesitan aún mayor contrastación empírica, más excavaciones y análisis en profundidad de los conjuntos arquitectónicos. No obstante, nuestra intención ha sido presentar un panorama general del cúmulo de información rescatada hasta este momento así como también transmitir nuestra interpretación de dichas evidencias, de modo tal que puedan servir como hipótesis de trabajo tanto a nuestras futuras investigaciones como a la de otros investigadores interesados en el tema.

\section{PATRONES DE ASENTAMIENTO Y USO DEL ESPACIO EN LA PRECORDILLERA DE ARICA. UN COMENTARIO FINAL}

Antes de presentar un comentario final de esta exposición, queremos señalar que el panorama expuesto es aún un modelo esquemático que presenta todavía muchos vacíos, de los cuales damos cuenta a continuación.

\section{1. Del Patrón Circular}

Las aldeas agrícolas han sido estudiadas solamente a manera prospectiva, aunque todas ellas cuentan con su respectivo levantamiento topográfico, análisis de material cerámico recolectado a través de pozos de sondeo y dataciones absolutas puntuales de los diversos sitios estudiados. No obstante, no sabemos aún si todas las aldeas descritas funcionaron contemporáneamente o si el conjunto de recintos de cada aldea es reflejo de una sincronía o representan más bien un proceso diacrónico que pondría en evidencia un crecimiento (o abandono) de las aldeas a través del tiempo.

Tampoco hemos dedicado mayor tiempo a esclarecer los patrones funerarios asociados a dichas aldeas. La presencia de Chullpas solo ha sido señalada y en contadas ocasiones descritas en su totalidad. De igual modo la relación de estas Chullpas con otras estructuras funerarias, i.e. cistas aéreas, coexistiendo en un mismo lugar, no ha sido debidamente aclarada. Otros aspectos no abordados sistemáticamente son la existencia de áreas para depósitos ya sea en las aldeas agrícolas o en los sitios defensivos. Tampoco ha sido abordado en profundidad el tema de los espacios abiertos delimitados por muros, comúnmente denominados «plazas».

\section{2. Del Patrón Rectangular}

Del mismo modo que en el tema anterior, las aproximaciones que hemos tenido a las instalaciones que conforman este patrón, pueden también considerarse como primeras aproximaciones. Al respecto hacen falta planos arquitectónicos más detallados y análisis constructivos (técnicas y 
materias primas) que permitan un análisis comparativo entre los distintos edificios y una propuesta de función más elaborada. Por otra parte, notamos una insuficiencia en las excavaciones realizadas hasta el momento, especialmente en la búsqueda de rasgos diagnósticos que orienten hacia una identificación más precisa del funcionamiento de las diversas instalaciones aquí reseñadas.

No obstante las deficiencias señaladas en los párrafos precedentes, el material acumulado en estos más de diez años de prospecciones e investigaciones a lo largo de la precordillera de Arica, permite exponer una visión integral de los patrones de asentamiento de esta zona durante los siglos X al XV. En dicho lapso de tiempo detectamos la presencia de dos importantes patrones constructivos. Uno, característico del período Intermedio Tardío y vinculado directamente a las poblaciones locales que denomináramos Patrón Circular. El otro, característico del período Tardío, asociado a la presencia Inca en la zona, fue denominado como Patrón Rectangular. No obstante dicha caracterización inicial, hacíamos presente que el Patrón Circular continuó vigente durante todo el período Tardío y hasta bastante entrada la Colonia, específicamente hasta el momento que el virrey Francisco de Toledo, en la década de 1570, emitiera las ordenanzas que redujeron a «pueblos de indios» a los diferentes sitios arqueológicos aquí reseñados, cambiando definitivamente el patrón de asentamiento por el denominado Patrón de Damero, característico de la presencia europea en toda América.

En cuanto al uso del espacio, este se caracteriza en gran medida, y hasta nuestros días, por el aprovechamiento agrícola de los sectores precordilleranos. Señalábamos en un comienzo que la precordillera de Arica esta formada por un conjunto de pequeños valles serranos que conforman cuatro cuencas hidrográficas de importancia: Lluta, Azapa, Codpa y Camarones. Durante el período Intermedio Tardío, cada uno de estos pequeños valles tenía una o más aldeas cuyos ocupantes estaban dedicados a una labor y economía preferentemente agrícola. Esta dedicación económica se evidencia principalmente por la inserción de diversas aldeas en un vasto sistema de terrazas agrícolas irrigadas mediante un complejo sistema de canales, cuyo manejo implicaría arreglos políticos entre las distintas aldeas que utilizaban un mismo sistema.

Paralelamente a las aldeas agrícolas, se evidencia durante este período un conjunto de sitios con una conformación similar a las aldeas pero diferentes de ellas por su ubicación estratégica en la cima de un cerro isla o en un sector abrupto de estas, por lo que han sido definidos como sitios defensivos o pucaras. Estas aldeas defensivas ponen de manifiesto una situación de conflicto que al parecer se estaba viviendo en toda la macrorregión andina hasta antes de la irrupción del orden incaico. En el caso de la zona en estudio este conflicto estaría siendo protagonizado por las poblaciones de valles y poblaciones altiplánicas, aunque hasta el momento, no contamos con los antecedentes necesarios que nos indiquen el predominio político de una población sobre otra; tampoco se ha podido detectar las estructuras políticas que prevalecieron en esa zona. La homogeneidad de estas aldeas y la presencia recurrente de pucaras en cada cabecera de valle, no ha permitido hasta el momento plantear diferencias importantes que posibiliten visualizar una posible jerarquización y por ende la identificación de centros políticos.

A diferencia de lo anterior, la llegada del Inca en la zona durante el período Tardío puso un énfasis en la administración de los recursos agrícolas locales y en el control de los valles bajos y de la costa del Pacífico mediante la instalación de centros administrativos en cada valle de importancia. El Inca, como en todo el resto del Incario, estableció su patrón de asentamiento a lo largo del eje vial, ubicado en este caso en la precordillera de Arica en una cota aproximada de $3600 \mathrm{msnm}$ y, en la periferia de las aldeas locales, ya sea en un extremo o aislado pero siempre en estrecha vinculación con éstas.

Por lo que sabemos hasta el momento, el Inca ejerció el control político de la región a través de los Señores del altiplano, presumiblemente Caranga. La presencia de Chullpas y la existencia de redes de caminos secundarios perpendiculares al camino de la sierra que unen altiplano y costa a lo largo de los valles, parecen refrendar este tipo de control político indirecto.

Teniendo en cuenta las consideraciones planteadas, vislumbramos que durante el período Tardío, el uso de espacio en el sector de precordillera, siguió teniendo su eje principal en el 
manejo de los recursos agrícolas existentes. La diferencia con el período anterior la constituye la presencia del estado Inca, el cual ejerció su control sobre la zona a través de una serie de instalaciones cuya función no estuvo vinculada a la producción sino al control de esta, dicha función fue llevada a cabo bajo términos político-administrativos y ceremoniales. De este modo el conjunto de instalaciones del Patrón Rectangular, asociado a la presencia Inca puede ser concebido como una red interactuante, en la que se combinan las funciones administrativas y políticas de determinados sitios con las funciones más ceremoniales de otros. La relativa cercanía de las diversas instalaciones incaicas en la zona, permitiría ver al conjunto actuando como un todo, o a lo menos para cada valle de importancia.

Esta red de caminos e instalaciones asociadas al Patrón Rectangular fue el mecanismo mediante el cual el estado Inca ejerció el control del territorio de Arica. En este trabajo hemos centrado nuestra atención en el sector de precordillera y hecho mención a algunas instalaciones de la puna. La imagen total de esta red se complementa con las instalaciones de los valles bajos: Molle Grande en Lluta (Santoro, 1997), Azapa 15 en Azapa (Santoro \& Muñoz, 1981); y Hacienda de Camarones en Camarones (Niemeyer \& Schiapacasse, 1988), todas éstas en una cota similar18.

Para finalizar, diré que a través de las páginas precedentes he presentado una visión sumaria e integral de un conjunto de sitios arqueológicos investigados en la precordillera de Arica, a través de los cuales se ha intentado dar forma a lo que fueran los patrones de asentamiento en dicha zona durante los siglos $\mathrm{X}$ al XV. Sabemos positivamente que aún falta mucho por precisar, no obstante, la visión de conjunto aquí entregada posibilita una buena comprensión de este espacio geográfico tanto en términos de lo que fue la ocupación prehispánica del área como en términos de nuevas hipótesis que se proyecten hacia futuras investigaciones.

\section{Referencias citadas}

ALDUNATE, C., 2001a - El Inka en Tarapacá y Atacama. In: Tras las Huellas del Inka en Chile: 19-44; Santiago: Museo Chileno de Arte Precolombino.

ALDUNATE, C., 2001b - Arquitectura y poder. In: Tras las huellas del Inka en Chile: 45-51; Santiago: Museo Chileno de Arte Precolombino.

BARTHEL, T., 1959 - Ein Frühlingsten der Atacameño. Zeitschrifst für Etnologie, 84 (1): 63-124 (citado y comentado por T. Zuidema, 1989).

BERTONIO, L., 1984 [1612] - Vocabulario de la lengua Aymara, 946 p.; Cochabamba: Centro Estudios Realidad Social-Instituto Francés de Estudios Andinos-Museo Etnografía y Folklore.

CHACAMA, J., BRIONES, L. \& MUÑOZ, I., 1989 - Puesta en valor de un sitio monumental prehispánico: EL tambo de Zapahuira (Az 40). Hombre y Desierto, 3-4: 23-37; Antofagasta: Universidadde Antofagasta.

CHACÓN, S. \& ORELLANA, M., 1979 - El Tambo Chungara. In: Actas VIII Congreso Nacional de Arqueología Chilena: 247-255; Valdivia: Editorial Kultrun.

CIEZA DE LEÓN, 1986 [1553-1554] - Crónica del Perú segunda parte; Lima: Pontificia Universidad Católica del Perú-Academia nacional de la Historia. Segunda edición.

18 No se ha detectado aún una instalación similar en el tramo bajo del valle de Codpa, pudiendo corresponder esta al sitio de Molle Grande 2, situación de la cual no estamos seguro. 
DAUELSBERG, P., 1983 - Investigaciones arqueológicas en la sierra de Arica. Chungara, 11: 63-83.

DAUELSBERG, P., 1995 [1959] - Contribución a la arqueología del valle de Azapa. Boletín Museo Regional de Arica (reedición boletines 1 al 7, L. Álvarez, coord.): 36-52; Arica: Universidad de Tarapacá.

DURSTON, A. \& HIDALGO, J., 1999 - La presencia andina en los valles de Arica, siglos XVIXVIII: casos de regeneración colonial de estructuras archipielágicas. Chungará, 29 (2): 249-273.

GASPARINI, G. \& MARGOLIES, L., 1980 - Inca architecture; Bloomington: Indiana University Press.

GUAMAN POMA, F., 1987 [1615] - Nueva crónica y buen gobierno (Murra, J., Adorno, R. \& Urioste, J., eds.), 1384 p.; Madrid: Historia 16.

HIDALGO, J., 1978 - Revisita de los altos de Arica efectuada por el oficial real don Joaquín de Cárdenas el año 1750; Arica: Universidad del Norte, departamento de arqueología.

HIDALGO, J., 1999 - Relaciones protohistóricas interétnicas entre las poblaciones locales y altiplánicas en Arica. In: La integración sur andina cinco siglos después (Albó, X. et al., comp.): 161-173; Cuzco: Centro de Estudios Bartolomé Las Casas.

HIDALGO, J., CASTRO, N. \& GONZÁLEZ, S., 2004 - La revisita de Codpa (altos de Arica) de 1772-1773. Efectuada por el corregidor Demetrio Egan. Chungará, 36 (1): 103-204.

HIDALGO, J. \& DURSTON, A., 1998 - Reconstitución étnica colonial en la sierra de Arica. El cacicazgo de Codpa 1650-1780. In: Actas del IV Congreso Internacional de Etnohistoria, Tomo II: 32-75; Lima: Pontificia Universidad Católica de Lima.

HIDALGO, J. \& SANTORO, C., 2001 - El estado Inca. In: Pueblos del desierto. Entre el Pacífico y los Andes: 74-84; Santiago: Editorial Universidad de Tarapacá.

HYSLOP, J., 1990 - Inka settlemente planning, 377 p.; Austin: Universidad de Texas Press.

HYSLOP, J., 1992 - Qhapaqñam. El sistema vial incaico, 298 p.; Lima: Instituto Andino de Estudios Arqueológicos.

LAGOS, R., MENDOZA, E. \& AMPUERO, R., 1982 - La noche de los abuelos en Santiago de Río Grande. Chungará, 9: 247-274.

LLAGOSTERA, A., 1976 - Hipótesis sobre la expansión incaica en la vertiente occidental de los Andes. In: Homenaje al Dr. Gustavo Le Paige: 203-218; Antofagasta: Universidad del Norte.

MICHELL, M., 2000 - El señorío prehispánico de Caranga. Universidad de La Cordillera. Ms.

MUÑOZ, I. \& BRIONES, L., 1998 - Poblados, rutas y arte rupestre precolombino de Arica: descripción y análisis de sistemas de organización. Chungará, 28 (1-2): 47-84.

MUÑOZ, I. \& CHACAMA, J., 1988 - Cronología por termoluminiscencia para los periodos Intermedio Tardío y Tardío en la sierra de Arica. Chungará, 20: 91-45.

MUÑOZ, I. \& CHACAMA, J., 1993 - El Inca en la sierra de Arica. In: Actas XII Congreso Nacional de Arqueología Chilena, Tomo I: 11-24; Temuco. Boletín Nº4 Museo Regional de la Araucanía, Sociedad Chilena de Arqueología, Dirección de Bibliotecas, Archivos y Museos, Museo Regional de la Araucanía, Temuco.

MUÑOZ, I. \& CHACAMA, J., 1997 - Uso del espacio y relaciones interculturales en la sierra de Arica: el caso de las sociedades prehispánicas del periodo Intermedio Tardío. In: Actas del II Congreso Chileno de Antropología: xx; Valdivia: Colegio de antropólogos de Chile.

MUÑOZ, I. \& CHACAMA, J., 1999 - Los valles de Arica y Tacna en la órbita de los Incas. In: Actas del XII Congreso Nacional de Arqueología Argentina (Diez de Marin, C., ed.): 262279; La Plata.

MUÑOZ, I. \& CHACAMA, J., 2005 (en prensa) - Complejidad social en las alturas de Arica: territorio, etnicidad y vinculación con el estado Inka; Ediciones Universidad de Tarapacá. 
MUÑOZ, I., CHACAMA, J., ESPINOSA, G. \& BRIONES, L., 1987a - La ocupación prehispánica tardía en Zapahuira y su vinculación a la organización económica y social Inca. Chungará, 18: 67-89.

MUÑOZ, I., CHACAMA, J. \& ESPINOSA, G., 1987b - El poblamiento prehispánico tardío en el valle de Codpa. Una aproximación a la prehistoria regional. Chungará, 19: 7-69.

MUÑOZ, I., CHACAMA, J. \& SANTOS, M., 1997 - Tambos, pukaras y aldeas, evidencias del poblamiento prehispánico tardío y de contacto indígena-europeo en el extremo norte de Chile: análisis de los patrones habitacionales y nuevas dataciones radiométricas. Diálogo Andino, 16: 123-191.

MUÑOZ, I. \& SANTOS, M., 198'8 - Desde el periodo Tiwanaku al indígena colonial: uso del espacio e interacción social en la quebrada de Miñita, norte de Chile. Diálogo Andino, 17: 69-114.

MUÑOZ, I. \& SANTOS, M., 2000 - Relaciones y estrategias de asentamientos humanos en el poblado prehispánico de Pubrisa, Arica: análisis de espacio habitacional y de la alfarería. Pacarina, X: 6-48.

MURRA, J., 1975 - El control vertical de un máximo de pisos ecológicos en la economía de las sociedades andinas. In: Formaciones económicas y políticas del mundo andino: 59-116; Instituto de Estudios Peruanos.

NIEMEYER, H. \& SCHIAPPACASSE, V., 1988 - Patrones de asentamiento incaicos en el norte grande de Chile. In: La frontera del estado Inca (Dillehay, T. \& Netherly, P., eds.): 141-180; Oxford: BAR International Series.

NIEMEYER, H., SCHIAPACASSE, V. \& SOLIMANO, I., 1972-1973 - Padrones de poblamiento en la quebrada de camarones. In: Actas del VII Congreso de Arqueología Chilena, Tomo II: 115-137; Santiago: Sociedad Chilena de Arqueología. Ed. Kultrun.

PACHACUTI, J., 1993 [1613] - Relación de antigüedades deste reyno del Piru (Duviols, P. \& C. Itier eds.), 276 p.; Lima: IFEA-CERA Bartolomé de Las Casas.

RIVIÈRE, G., 1982 - Sabaya: strucures socio-écomonique et réprésentations symboliques dans les Carangas. Bolivie. Tesis doctoral de etnología 3er ciclo. Paris: École de Hautes Études en Sciences Sociales.

ROMERO, A., 1999 - Ocupación multiétnica en la sierra de Arica: arquitectura, uso del espacio y distribución cerámica en el poblado arqueológico de Huaihuarani. http://uta.cl/masma/ azeta/hauiha

ROMERO, A., 2002 - El pucara de Caillama, las Chulpas de barro y el control político de la sierra de Arica durante el periodo Intermedio Tardío. http://www.uta.cl/masma/azeta/ caillama.

ROMERO, A. \& BRIONES, L., 1999 - Estado y planificación Inca en Collahuasi. Estudios Atacameños, 18: 141-154.

SANTORO, C., 1983 - Camino del Inca en la sierra de Arica. Chungara, 10: 39-46.

SANTORO, C., 1997 - Complejidad social en los valles desérticos del extremo norte de Chile y sur del Perú. http://www.uta.cl/masma/yuta

SANTORO, C., HIDALGO, J. \& OSORIO, A., 1987 - El estado Inka y los grupos étnicos en el sistema de riego de Socoroma. Chungará, 19: 71-92.

SANTORO, C \& MUÑOZ, I., 1981 - Patrón habitacional incaico en el área de pampa Alto Ramirez (Arica - Chile). Chungará, 7: 144-171.

SANTORO, C., ROMERO, A., STANDEN, V. \& TORRES, A., 2000 - Continuidad y cambio en las comunidades locales. Periodos Intermedio Tardío y Tardío en los valles occidentales, área centro Sur Andina. http://www.uta.cl/masma/yuta

SCHIAPPACASSE, V. \& NIEMEYER, H., 1997 - Continuidad y cambio cultural en el poblado actual, colonial e inca de Pachica, Quebrada de Camarones. Chungará, 28 (1-2): 209-247. 
SCHIAPPACASSE, V. \& NIEMEYER, H., 2002 - Ceremonial Inca Provincial: El asentamiento de Sagura (Cuenca de Camarones). Chungará, 34 (1): 53-84.

TRELLES, E., 1991 - Lucas Martínez Vegazo: funcionamiento de una encomienda peruana inicial; Lima: Pontificia Universidad Católica del Perú.

ZUIDEMA, T., 1989 - Lugares sagrados e irrigación: tradición histórica, mitos y rituales en el Cuzco. In: Reyes y guerreros. Ensayos de cultura andina (Burga, M., ed.): 455-487; Lima.

ZUIDEMA, T., 1995 - El sistema de los Ceques del Cuzco. La organización social de la capital de los Incas, 420 p.; Lima: Pontificia Universidad Católica del Perú. 